\title{
Peer Teaching Promotes Improved Knowledge and Attitudes about MyPlate and SuperTracker among College Students and Increases Self-Efficacy in Peer Nutrition Educators
}

\author{
Danielle Jerome, Sandra Baker*, Cheng-Shun Fang \\ Behavioral Health and Nutrition, University of Delaware, Newark, USA \\ Email:djerome@udel.edu, bakers@udel.edu,rfang@udel.edu
}

How to cite this paper: Jerome, D., Baker, S., \& Fang, C.-S. (2018). Peer Teaching Promotes Improved Knowledge and Attitudes about MyPlate and SuperTracker among College Students and Increases Self-Efficacy in Peer Nutrition Educators. Creative Education, 9, 979-992.

https://doi.org/10.4236/ce.2018.96072

Received: April 4, 2018

Accepted: May 28, 2018

Published: May 31, 2018

Copyright $\odot 2018$ by authors and ScientificResearch Publishing Inc. This work is licensed under the CreativeCommons Attribution International

License (CC BY 4.0).

http://creativecommons.org/licenses/by/4.0/

\begin{abstract}
Background: Peer teaching to college students can be an effective method for improving knowledge and attitudes toward healthy eating. MyPlate and SuperTracker tools are valuable resources for healthy meal planning. However, awareness and knowledge of these tools are necessary to effect change. Objective: To evaluate university students' knowledge and attitudes about the USDA's MyPlate icon and SuperTracker tools before and after peer teaching by a nutrition major. Design: Cross-sectional online pre and post-survey administered to participants before and after peer teaching. Participants/Setting: 264 mixed majors enrolled in First Year Experience (FYE) classes at a large university were peer taught by upper class undergraduate nutrition majors on a relevant nutrition topic in 20-minute presentations that featured MyPlate and SuperTracker tools. Statistical analyses performed: Descriptive statistics (frequencies, percentages) were used for categorical variables and parametric tests (independent paired t-test) were used for continuous variables. $P<.05$ was considered statistically significant. Results: The majority of participants were female $(68.2 \%)$, freshmen (53.8\%), white (83\%), and non-nutrition majors (96.2\%). Both males and females indicated favorable views towards the MyPlate icon post-presentation. From pre to post presentation, responses related to knowledge about portions $(p<.001)$ and reminders to eat healthfully increased significantly $(p<.001)$. After the presentation, $92.4 \%$ of students agreed that SuperTracker tools are useful for college students, and $88.6 \%$ thought they could benefit from using them. A confidential online survey was completed by the peer nutrition educators after their teaching experience. All who responded (14/16) indicated that their presentation skills improved as a result of the experience. Conclusion: Peer teaching is an effective way to
\end{abstract}


promote healthy eating behaviors in college students, improve presentation skills of the peer educators, and can easily be incorporated into FYE classes across college campuses.

\section{Keywords}

Peer Teaching, College Students, MyPlate, SuperTracker, Self-Efficacy

\section{Introduction}

As students enter college, they are faced with many challenges including those that influence their health (Kelly, Mazzeo, \& Bean, 2013; Li et al., 2012; Matthews, Doerr, \& Dworatzek, 2016). Among those challenges are the possibilities of adopting poor eating habits (Vadeboncoeur, Townsend, \& Foster, 2015; Lua, \& Wan Putri Elena, 2012) and gaining weight (Vadeboncoeur, Townsend, \& Foster, 2015). Weight gain during adolescence is strongly associated with overweight and obesity in adulthood (Ogden et al., 2015). Obesity is a risk factor for hypertension, heart disease, diabetes, stroke, and cancer (Jensen et al., 2014). With over $60 \%$ of freshman gaining an average of 3 pounds in their first 6 weeks to eight months of school (Vadeboncoeur, Townsend, \& Foster, 2015) and more than one-third (36.5\%) of U.S. adults classified as obese (Ogden et al., 2015), effective nutrition interventions are needed (Jensen et al., 2014). Some factors that may contribute to weight gain during college include stress, consumption of alcohol, poor nutritional habits, physical activity decline (Vadeboncoeur, Townsend, \& Foster, 2015; Lua \& Wan Putri Elena, 2012), and inadequate nutritional knowledge and positive attitudes (Dissen et al., 2011). Studies have indicated that college students consume less than the recommended servings of vegetables and fruits per day (Li et al., 2012; Yahia et al., 2016; Thompson et al., 2015) and consume excess intake of sodium, saturated fat, and high-calorie beverages (Slining \& Popkin, 2013).

In a recent study by D'Souza et al., students living on a college campus had statistically significant higher BMIs than those living off-campus which the authors alluded to the buffet-style dining hall (D’Souza et al., 2015). Based on the outcomes of this study, the authors concluded that the students needed interventions to help them make healthier decisions with regard to food intake. As a result, the college started a new core-curriculum in which all freshmen students are required to take a First Year Experience (FYE) course, that includes different health topics (D'Souza et al., 2015). Although this is a strong first step toward fighting this epidemic, the effectiveness of nutrition interventions to help college students improve dietary behaviors is limited (Kelly, Mazzeo, \& Bean, 2013; Lua \& Wan Putri Elena, 2012).

Nutrition interventions such as nutrition education classes, one-on-one nutrition education sessions, online education, point-of-purchase (POP) interven- 
tions, and supplement provision have been reviewed (Kelly, Mazzeo, \& Bean, 2013; Lua, \& Wan Putri Elena, 2012). Some of the interventions showed promise. Recommendations from these findings include: development of engaging and practical nutrition education tools, nutrition education for first-year university students (Lua \& Wan Putri Elena, 2012), and inclusion of self-regulation strategies and activities to promote self-efficacy in promoting dietary behavior change (Kelly, Mazzeo, \& Bean, 2013).

A strong sense of self-efficacy, one's belief in one's ability to succeed, is vital for personal success (Bandura, 1998). Personal self-efficacy is a construct of Social Cognitive Theory (SCT); interventions that are based on SCT have a strong effect on changing dietary habits (Peterson et al., 2010). Modeling the behavior of others, according to SCT, increases knowledge while developing the skills and strategies needed to manage the environment (Bandura, 1998). Peer education is a way for students to model healthy habits and can be an effective method for improving self-efficacy, perceptions, and attitudes toward healthy eating (Nickols-Richardson, Nelson, \& Corbin, 2014) and physical activity (Topp et al., 2014). It provides a more student-centered environment and enhances learning for both educators and students (Gucciardi, Mach, \& Mo, 2016). Peer educators reduce anxiety and increase participation in the classroom while increasing their mastery of the subject (Gucciardi, Mach, \& Mo, 2016). It is important that peer educators are properly trained (Cooke et al., 2015; Khan et al., 2009) as high self-efficacy in peer educators leads to students with higher self-efficacy (Cooke et al., 2015). Nutrition students who are peer educators should receive guidance and support from their instructors while gaining experience teaching (Cooke et al., 2015).

Since its induction in 2011, MyPlate has been the USDA's vehicle for Americans to eat healthy and was introduced along with the 2010 Dietary Guidelines for Americans (DGA) (US Department of Agriculture, 2017). Many Americans are familiar with the MyPlate icon but limited research has been conducted to evaluate its effectiveness in behavior change (Guthrie, Mancino, \& Lin, 2015). A study that used National Health and Nutrition Examination Survey Data (NHANES) from 6464 participants ( $>16$ years of age) found that $20.2 \%$ had heard of MyPlate and of those, 33.2\% looked it up online, and 35.3\% tried to follow it. A strong correlation was found between those who were familiar with MyPlate and using nutrition information (i.e. on menus) when eating outside the home (i.e. fast-food outlet, restaurant) ( $p<.05$ for all subgroups) (Tagtow \& Raghavan, 2017). A six-lesson Youth Understanding MyPlate (YUM) curriculum was taught to elementary school students $(n=535)$ who were part of Florida's SNAP-Education program (Coker et al., 2016). The YUM program teaches the messages of MyPlate through activities geared toward each specific grade level. At the end of the lessons, students reported an increased intake of fruits/vegetables, whole grains, low fat/fat-free dairy, healthier snacks, eating breakfast, and physical activity compared to baseline $(p<.001)$ (Coker et al., 
2016).

To better understand how college students view the MyPlate icon and its website, an online survey asking questions about MyPlate and its website was developed and distributed to college students on a large university campus $(n=564)$ (Baker, 2013). Students were either enrolled in an introductory nutrition course, were nutrition majors, or part of the general student population $(n=564)$. Results showed that over half of those surveyed agreed that the icon was appealing but $64.6 \%$ disagreed or were not sure that the icon inspired them to view the website (Baker, 2013). Those who did explore the site had more positive opinions about MyPlate (Baker, 2013).

In 2016, the ChooseMyPlate website received a facelift with a new modernized design and updated messages to reflect the 2015 DGA (Herring et al., 2016). New features include: an interactive MyPlate on the homepage website, organization by audience; social media sharing; and clearer access to online tools such as SuperTracker (Herring et al., 2016). SuperTracker is an interactive food, physical activity, and weight tracking tool that helps Americans put the DGA into practice (Herring et al., 2016). This redesign may encourage college students to use the tools if they are made aware of the website and its multiple functions.

Increased awareness of MyPlate and its website appears to be a possible determinant in behavior change (Coker et al., 2016). With increases in weight, poor nutritional habits, and lack of nutrition knowledge and awareness, college students may benefit from an effective nutrition intervention that includes MyPlate education and peer teaching to improve self-efficacy. In 2013, focus groups of undergraduate students $(n=27)$ who took a nutrition course (non-nutrition majors) at the same university campus (Baker, 2013), provided feedback on effective teaching methods of MyPlate (Baker, 2014). This helped establish ideas for delivering a program that would appeal to undergraduate students; these ideas culminated in creation of a one credit course "MyPlate Ambassadors" for junior and senior nutrition majors which focused on building majors' skills in creating and delivering nutrition presentations appealing to a college audience (Baker, 2016). The course featured a collaborative style with the instructor serving as coach to students who learned about MyPlate and SuperTracker resources and then developed and delivered four engaging presentations to fellow students. After obtaining Institutional Review Board approval, a pre and post study were conducted on one of the presentations and the results of this pilot study informed the design of this current study (Baker, 2016).

The investigators wanted to further explore the effects of peer teaching to a larger group with varied majors and present one topic that was delivered consistently through adequate training and practice. Therefore, the purpose of this study was to evaluate university students' knowledge and attitudes about the USDA's MyPlate icon and SuperTracker tools before and after peer teaching. 


\section{Methods}

This study consists of PNEs training students who were in First Year Experience (FYE) courses as participants. Surveys were conducted before and after training to participants and post-training to PNEs.

\subsection{Peer Nutrition Educator Recruitment and Training}

The "MyPlate Ambassador" one credit class was taught a second time in the fall of 2016 and nutrition majors were selected for enrollment after completing an application and interview. Sixteen students were selected (5 juniors/11 seniors) as Peer Nutrition Educators (PNEs). The first three classes consisted of a thorough review of the MyPlate, SuperTracker, and online tools/resources available on the ChooseMyPlate.gov site. All students completed the MyPlate Ambassador Training available on the ChooseMyPlate website. Students also received instruction on principles for creating an engaging presentation. Next, students collaborated together with the instructor coaching in creating a 20-minute presentation designed with college students' needs in mind. They chose to focus on portion control as they believed this was an important but misunderstood topic among their peers. The PowerPoint presentation included video clips, humor, as well as evidence-based content. An explanation of the MyPlate icon and thorough demonstration of SuperTracker were included. After class members and the instructor had revised and edited the presentation, the finalized version with script was completed. To ensure consistency in presentation delivery, all 16 of the Peer Nutrition Educators practiced the presentation in front of the instructor and each other while receiving constructive feedback.

The 20-minute presentation and pre- and post-surveys in this study were designed to appeal to the college students in the FYE classes with anticipation of reaching a large number of students from different majors.

\subsection{Participants}

As of the fall of 2016, 17,669 undergraduates were enrolled in the University of Delaware in Newark, DE. Of those, 4454 or $25.2 \%$ were freshmen (University of Delaware, 2017). FYE Programs are offered to students to help adjust to college life with learning and exploration (University of Delaware, 2017). All students take the FYE classes regardless of major or college.

An email was sent out to the FYE instructors offering the presentation along with a sign-up sheet with dates and times. A total of nine classes were taught by the eight pairs of PNEs with class size ranging from 20 to 50 students. The PNEs taught the class in pairs and also had fellow PNEs observe and give feedback to help ensure consistency in the delivery and to enrich the learning experience.

\subsection{Participant Surveys}

The pre- and post-surveys were modified based on the pilot study and adapted to an online version as Google forms. Each of the surveys was assigned a unique 
link for online access. Paper surveys identical to the online surveys were readily available for anyone who could not access the online version. Pilot testing was conducted for ease of use and content of the online survey by 2 instructors and the 16 PNEs. Both online and paper survey versions described the research study and stated that participants must be at least 18 years of age and completion of the survey implied consent to participate.

Survey content included questions about MyPlate familiarity and opinion, skills and knowledge related to portion sizes, SuperTracker familiarity and opinion, and presenter skills (post-survey only).Survey questions were on a 5-point Likert scale, open-ended, or "check all that apply" format.

Prior to beginning the presentation, a pair of PNEs provided each class member with a unique code and the link to the pre-survey. The unique 4 -digit code was entered on the first line of the survey and was used for both pre-and post-surveys in order to match the students' responses; no other identifiers were used. Each survey was designed to take less than 5 minutes to complete. The online survey would automatically terminate if a student responded that he/she was less than 18 years of age. Once the pre-surveys were completed, the 20-minute PowerPoint lesson was co-taught by the PNEs after which the post-survey link was provided. The post-survey concluded the lesson.

\subsection{PNEs Survey}

At the conclusion of the MyPlate Ambassador course, the PNEs completed an eight-question online survey. The survey questions were either open-ended or Likert scale and were designed to gain feedback about the experience. The $\mathrm{Hu}$ man Subjects Review Board at the University of Delaware approved the protocol, consent forms, and all survey instruments.

\subsection{Statistical Analysis}

Analyses were conducted using IBM SPSS Statistics Grad Pack (version 24.0, 2016) (IBM SPSS Statistics Grad Pack, 2016). Descriptive Statistics (frequencies, percentages), were used for categorical variables and parametric test (independent paired t-test) were used for continuous variables. $P<.05$ was considered statistically significant.

\section{Results}

Initially, 366 pre-surveys and 275 post-surveys were completed. Surveys were excluded if less than 18 years of age $(n=4)$, missing pre-surveys $(n=5)$ or post-surveys $(n=67)$ or unassigned codes $(n=26)$. The total matching pre/post surveys was 264 .

The demographics/characteristics of the participants are shown in Table 1. The majority of the students were female $(68.2 \%, \mathrm{n}=180)$, freshmen $(53.8 \%, \mathrm{n}=$ $142)$, white $(83 \%, \mathrm{n}=219)$, and non-nutrition majors $(96.2 \%, \mathrm{n}=254)$.

Out of the 264 survey participants, 52 (19.7\%) answered "no" when asked if 
they had ever seen the MyPlate icon. For those who were familiar with the icon prior to the presentation $(\mathrm{n}=212,80 \%)$, the majority felt that MyPlate had a "clear message" and was "easy to follow" when asked what they liked best about it (Table 2). After the presentation, the post-survey responses $(n=264)$ agreed with the pre-survey responses with a majority also choosing "shows what foods to eat" when asked the same question. When answering what they liked least about the icon, "boring" and "basic" were the two most common negative opinions in both surveys. However, the most frequent response in both surveys was "There is nothing I dislike about it" in reference to the icon. In the post-survey, $65.5 \%$ of the respondents reported that their opinion of MyPlate "positively changed" after hearing the presentation (Table 2).

Using a 5-point Likert scale, participants were asked whether they "agree" or "disagree" with the MyPlate icon "reminding them to eat healthfully" $(1=$ strongly disagree, 5 = strongly agree). A paired samples t-test was used to compare opinions before and after the presentation $(\mathrm{n}=212)$. Results showed a significant increase in scores from pre $(\mathrm{M}=3.21, \mathrm{SD}=.895)$ to post-survey $(\mathrm{M}=$ 3.87, $\mathrm{SD}=.912, \mathrm{t}(211)=-11.44, p<.001)$ as shown in Table 3. In the pre-survey, the mean score of 3.21 indicated mostly neutral opinion as opposed to the post-survey mean of 3.87 which showed a trend toward agreement or

Table 1. Participant demographics of those who attended a first year experience (FYE) class taught by peer nutrition majors on a college campus.

\begin{tabular}{|c|c|c|c|}
\hline & Characteristic & Total $(\mathrm{n}=264)$ & $\%$ \\
\hline \multicolumn{4}{|l|}{ Sex } \\
\hline & Male & 84 & 31.8 \\
\hline & Female & 180 & 68.2 \\
\hline \multicolumn{4}{|l|}{ Year } \\
\hline & Freshmen & 142 & 53.8 \\
\hline & Sophomore & 54 & 20.5 \\
\hline & Junior & 33 & 12.5 \\
\hline & Senior & 35 & 13.3 \\
\hline \multicolumn{4}{|l|}{ Race } \\
\hline & White & 219 & 83.0 \\
\hline & Black/African American & 12 & 4.5 \\
\hline & Hispanic/Latino American & 13 & 4.9 \\
\hline & Asian American & 11 & 4.2 \\
\hline & Other & 9 & 3.4 \\
\hline \multicolumn{4}{|l|}{ Nutrition Major } \\
\hline & Yes & 10 & 3.8 \\
\hline & No & 254 & 96.2 \\
\hline
\end{tabular}


Table 2. Pre and post-survey results regarding MyPlate of participants who attended a first year experience class taught by peer nutrition majors on a college campus.

\begin{tabular}{|c|c|c|c|c|}
\hline & Pre-survey & & Post-surve & \\
\hline & Total $(\mathrm{n}=212)^{\mathrm{a}}$ & $\%$ & Total $(\mathrm{n}=264)$ & $\%$ \\
\hline $\begin{array}{l}\text { Have you seen the MyPlate icon } \\
\text { prior to taking this survey? }\end{array}$ & 212 & 80.3 & & \\
\hline What do you like best about MyPlate? & & & & \\
\hline Clear message & 117 & 55.2 & 160 & 60.6 \\
\hline Easy to follow & 166 & 78.3 & 196 & 74.2 \\
\hline Shows what foods to eat & 89 & 42.0 & 142 & 53.8 \\
\hline What do you like Least about MyPlate & & & & \\
\hline Boring & 35 & 16.5 & 41 & 15.5 \\
\hline Too Basic & 56 & 26.4 & 59 & 22.3 \\
\hline Nothing & 111 & 52.3 & 160 & 60.6 \\
\hline After hearing the mini-presentation, ho & your opinion of $\mathrm{N}$ & Plate c & nged? & \\
\hline Negative $(1,2)$ & & & 7 & 2.7 \\
\hline Neutral (3) & & & 84 & 31.8 \\
\hline Positive $(4,5)$ & & & 173 & 65.5 \\
\hline
\end{tabular}

aThose included who have seen MyPlate icon.

Table 3. Pre and post-survey responses to statement, "MyPlate reminds me to eat healthfully" by participants who attended a First Year Experience class taught by peer nutrition majors on a college campus.

\begin{tabular}{cccc}
\hline & $\begin{array}{c}\text { Pre-Survey } \\
\text { Total }(\mathrm{n}=212)^{\mathrm{a}}\end{array}$ & $\begin{array}{c}\text { Post-survey } \\
\text { Total }(\mathrm{n}=212)^{\mathrm{a}}\end{array}$ & p-value \\
\hline Mean $^{\mathrm{b}}(\mathrm{SD})^{\mathrm{c}}$ & $3.21(\mathrm{SD} .895)$ & $3.87(\mathrm{SD} .912)$ & $<.001$ \\
\hline
\end{tabular}

aThose included who have seen MyPlate; ${ }^{\mathrm{b} B a s e d}$ on Likert scale, 1 - 5 (1 = strongly disagree, 5 = strongly agree); ' SD Standard Deviation.

strong agreement of reminding them to eat healthfully.

In Table 4, a Likert scale was used to evaluate the impact of the lesson on knowing the difference between a portion and a serving size. A paired samples $\mathrm{t}$-test showed a significant increase in participants' self-confidence from before the lesson $(\mathrm{M}=3.11, \mathrm{SD}=1.25)$ to after the lesson $(\mathrm{M}=4.64, \mathrm{SD}=.644, \mathrm{t}(263)$ $=-19.97, p<.001)$. Pre-survey data indicated neutral agreement in distinguishing differences between a portion and serving size whereas the post-survey data showed strong agreement in the ability to distinguish the differences. The second portion question (5-point Likert scale) measured how participants' knowledge changed from pre to post lesson in being able to name 3 tips to control portions. There was a statistically significant increase in knowledge from pre $(\mathrm{M}=2.88, \mathrm{SD}=1.17)$ to post survey $(\mathrm{M}=4.58, \mathrm{SD}=.677, \mathrm{t}(263)=-22.42, p$ $<.001)$ also shown in Table 4. In the pre-survey, the mean (2.88) response was below neutral $(<3)$ indicating limited knowledge. The post-survey showed a 
large increase in knowledge with a mean (4.58) response in strong agreement $(>4)$.

In the pre-survey, only 41 out of 264 participants (15.5\%) had ever heard of the USDA's SuperTracker tool. Of those 41 participants, 24 (58.5\%) had ever used SuperTracker (Table 5). After the presentation, 264 (92.4\%) participants "agreed" or "strongly agreed" that SuperTracker tools are useful for college students and 234 (88.6\%) participants thought they could benefit from using them (Table 6).

\subsection{PNE Survey}

When asked if their presentation skills improved, $100 \%$ of the PNEs responded "yes" $(n=14)$. When asked if they liked the style where the student is the leader and the instructor is the coach, $100 \%$ liked it and provided reasons why. In write-in responses about what they liked best about the class, most said they gained experience. Some of the representative comments were, "I feel more

Table 4. Pre and post-survey responses by participants who attended a First Year Experience (FYE) class taught by peer nutrition majors on a college campus.

\begin{tabular}{|c|c|c|c|}
\hline Mean Responses ${ }^{\mathrm{a}}$ to statements & $\begin{array}{c}\text { Pre-Survey } \\
\mathrm{n}=264\end{array}$ & $\begin{array}{c}\text { Post-Survey } \\
\mathrm{n}=264\end{array}$ & p-value \\
\hline $\begin{array}{c}\text { I know the difference between a "portion" } \\
\text { and a "serving size" }\end{array}$ & $3.11(\mathrm{SD} 1.25)^{\mathrm{b}}$ & $4.64(\mathrm{SD} .644)$ & $<.001$ \\
\hline I can list 3 tips for controlling portions & $2.88(\mathrm{SD} 1.17)^{\mathrm{b}}$ & $4.58(\mathrm{SD} .677)$ & $<.001$ \\
\hline
\end{tabular}

Table 5. Survey results about SuperTracker tools prior to hearing a peer taught nutrition presentation by participants who took a First Year Experience (FYE) class.

\begin{tabular}{ccc}
\hline Have you ever heard of SuperTracker? & Total $\mathrm{n}=264$ & $\%$ \\
\hline Yes & 41 & 15.5 \\
No & 223 & \\
Have you ever used SuperTracker? & $\mathrm{n}=41$ & 58.5 \\
Yes & 24 & 41.5 \\
No & 17 & 4 \\
\hline
\end{tabular}

Table 6. Survey results about SuperTracker tools of participants who took a First Year Experience class after hearing a peer taught nutrition presentation.

\begin{tabular}{ccc}
\hline SuperTracker tools are useful & Total $\mathrm{n}=264$ & $\%$ \\
\hline Agree & 244 & 92.4 \\
Disagree & 20 & 7.6 \\
I could benefit from using SuperTracker tools & & \\
Agree & 234 & 88.6 \\
Disagree & 30 & 11.4 \\
\hline
\end{tabular}


confident now when presenting" and "This class style also gave us more independence and problem-solving skills." Suggestions for ways to recruit more participants were given as well as topics for future classes. The most frequent topic recommended for future classes to be taught by the PNEs was "Making healthier food selections in the dining hall".

\section{Discussion}

The results of this survey support peer teaching in the university setting. The online survey format was very effective in a college classroom where students had laptops and cellphones to access the survey easily. The target audience, the FYE students, were mostly freshmen and in need of academic and life skills (Schrader \& Brown, 2008). FYE programs on college campuses are designed to help students succeed personally, academically, and socially (University of Delaware, 2017). At the university where this study took place, the FYE classes offer many different topics throughout the course.

The peer teaching by well-trained undergraduate nutrition majors to mixed majors in the FYE classes resulted in positive outcomes for both the participants and the PNEs. These results are congruent with other studies using peer education to improve overall wellness (Thompson et al., 2015; Topp et al., 2014; Khan et al., 2009).

One example of peer education improving overall wellness was demonstrated in a study by Thompson et al, where dietetic interns teamed up with a registered dietitian to give tours at a local grocery store with the goal of improving fruit and vegetable intake in undergraduate college students (Thompson et al., 2015). After proper training, the interns gave interactive tours to college students who were enrolled in a general nutrition education class; the tour focused solely on fruits and vegetables. In the post-tour surveys, the majority of the participants (69\%) indicated that they would definitely eat more fruits and vegetables, and $50 \%$ of the students tasted a new fruit or vegetable during the tour. The interns also benefitted from improving their oral communication skills and gaining experience in retail dietetics (Thompson et al., 2015). With adequate training and monitoring, peer education can be a successful method for improved health behavior and attitudes (Thompson et al., 2015; Topp et al., 2014; Khan et al., 2009).

Although most of the participants in this study were already familiar with the MyPlate icon (80\%), they had a more favorable opinion of MyPlate after hearing the presentation. They also agreed that MyPlate reminded them to eat healthfully with a mean of 3.87 out of 5 (agree to strongly agree). Knowledge gained was significant from pre to post presentation as evidenced by the portion questions. It is surprising that only $15.5 \%$ of this group had ever heard of SuperTracker which was launched in 2011 and as of 2015 had over 5.5 million users (US Department of Agriculture, 2015). After seeing the tool's multiple features during the lesson, students responded strongly that they felt it was useful (92.4\%) and believed they could benefit from using it (88.6\%). 
Due to the design and duration of the study, actual behavior change could not be assessed. However, the intervention increased the PNEs' self-efficacy through improvements in their self-confidence and presentation skills as indicated in the PNE survey.

The major strengths of this study include the effective use of trained peer educators, anonymity of the participants, good representation of the campus population, adequate sample size, and consistency in delivery of nutrition content. The limitations of this study are its short duration of the PNE presentation, limited number of presentations due to competing interests in the FYE classes, lack of diversity in race/ethnicities, and possible influence of those who already had an interest in nutrition affecting the results. However, this peer education model demonstrates effectiveness for its intent to improve knowledge and attitudes of MyPlate and SuperTracker and can be expanded upon to include more nutrition topics of interest to the population, other ethnicities/races, a follow-up component to assess behavior change, and technology that is appealing to the participants.

\section{Conclusion}

Increasing self-efficacy in the college population to promote dietary behavior change requires interventions that involve trained peer educators, provide relatable nutrition education, reach FYE students, and use creative strategies. This study captured most of these areas. In conclusion, peer teaching by nutrition majors that included demonstration of MyPlate and SuperTracker tools resulted in increased knowledge and attitudes in college students enrolled in FYE classes on a large university campus and increased self-efficacy in the PNEs. Peer teaching is an effective way to promote healthy eating behaviors in college students and can easily be incorporated into FYE classes across college campuses.

\section{Research Snapshot}

Research question/purpose: The purpose of this study was to evaluate university students' knowledge and attitudes about the USDA's MyPlate icon and SuperTracker tools before and after peer teaching by a nutrition major.

Key findings: In this cross-sectional study, 264 online pre and post-surveys were completed by university students enrolled in First Year Experience classes before and after peer nutrition presentations. From pre to post presentation, responses indicated significant increases in knowledge about portions as well as improved attitudes toward SuperTracker and MyPlate. Additionally, all of the peer educators who completed a confidential survey reported improved presentation skills.

\section{Interest}

Financial disclosures: none.

Conflict of interest disclosures: There were no conflicts of interest. 


\section{References}

Baker, S. D. (2013). College Students' Perceptions of MyPlate and ChooseMyPlate.gov. Journal of the Academy of Nutrition and Dietetics, 113, A82. https://doi.org/10.1016/j.jand.2013.06.288

Baker, S. D. (2014). Suggestions for Teaching MyPlate and Its Website in University Nutrition Courses. Journal of the Academy of Nutrition and Dietetics, 114, A89. https://doi.org/10.1016/j.jand.2014.06.302

Baker, S. D. (2016). Curriculum Equips Nutrition Majors to Share MyPlate on Campus. Journal of Nutrition Education and Behavior, 48, S38-S39. https://doi.org/10.1016/j.jneb.2016.04.104

Bandura, A. (1998). Health Promotion from the Perspective of Social Cognitive Theory. Psychology \& Health, 13, 623-649. https://doi.org/10.1080/08870449808407422

Coker, C., Shelnutt, K., Headrick, L., Sari, H., \& Hart, C. (2016). Youth Understanding of MyPlate Improves Behaviors of Elementary School Students. Journal of Nutrition Education and Behavior, 48, S23. https://doi.org/10.1016/j.jneb.2016.04.063

Cooke, N. K., Ash, S. L., Nietfeld, J. L., Fogleman, A. D., \& Goodell, S. L. (2015). Impact of a Service-Learning-Based Community Nutrition Course on Students' Nutrition Teaching Self-Efficacy. NACTA Journal, 59, 28-33. https://doi.org/10.1016/j.jneb.2015.04.013

D’Souza, M. J., Walls, K. E., Rojas, C., Everett, L. M., \& Wentzien, D. E. (2015). Effect of Gender and Lifestyle Behaviors on BMI Trends in a Sample of the First State's Undergraduate Population. The American Journal of the Medical Sciences, 6, 59-74.

Dissen, A. R., Policastro, P., Quick, V., \& Carol, B.-B. (2011). Interrelationships among Nutrition Knowledge, Attitudes, Behaviors and Body Satisfaction. Health Education, 111, 283-295. https://doi.org/10.1108/09654281111144256

Gucciardi, E., Mach, C., \& Mo, S. (2016). Student-Faculty Team Teaching-A Collaborative Learning Approach. Mentoring \& Tutoring: Partnership in Learning, 24, 441-455. https://doi.org/10.1080/13611267.2016.1270899

Guthrie, J., Mancino, L., \& Lin, C. J. (2015). Nudging Consumers toward Better Food Choices: Policyapproaches Tochanging Food Consumption Behaviors. Psychol Mark, 32, 501-511. https://doi.org/10.1002/mar.20795

Herring, D., Chang, S., Bard, S., \& Gavey, E. (2016). Five Years of MyPlate-Looking Back and What's Ahead. Journal of the Academy of Nutrition and Dietetics, 116, 1069-1071. https://doi.org/10.1016/j.jand.2016.05.001

IBM SPSS Statistics Grad Pack (2016). Version 24.0. Armonk, New York: IBM Marketplace.

Jensen, M. D., Ryan, D. H., Apovian, C. M., et al. (2014). 2013 AHA/ACC/TOS Guideline for the Management of Overweight and Obesity in Adults. Journal of the American College of Cardiology, 63, 2985. https://doi.org/10.1016/j.jacc.2013.11.004

Kelly, N. R., Mazzeo, S. E., \& Bean, M. K. (2013). Systematic Review of Dietary Interventions with College Students: Directions for Future Research and Practice. Journal of Nutrition Education and Behavior, 45, 304-313. https://doi.org/10.1016/j.jneb.2012.10.012

Khan, N. A., Nasti, C., Evans, E. M., \& Chapman-Novakofski, K. (2009). Peer Education, Exercising, and Eating Right (PEER): Training of Peers in an Undergraduate Faculty Teaching Partnership. Journal of Nutrition Education and Behavior, 41, 68-70. https://doi.org/10.1016/j.jneb.2008.03.116

Li, K., Concepcion, R. Y., Lee, H. et al. (2012). An Examination of Sex Differences in Re- 
lation to the Eating Habits and Nutrient Intakes of University Students. Journal of Nutrition Education and Behavior, 44, 246-250. https://doi.org/10.1016/j.jneb.2010.10.002

Lua, P. L., \& Wan Putri Elena, W. D. (2012). The Impact of Nutrition Education Interventions on the Dietary Habits of College Students in Developed Nations: A Brief Review. Malaysian Journal of Medical Sciences, 19, 4-14.

Matthews, J. I., Doerr, L., \& Dworatzek, P. D. N. (2016). University Students Intend to Eat Better But Lack Coping Self-Efficacy and Knowledge of Dietary Recommendations. Journal of Nutrition Education and Behavior, 48, 12-19. https://doi.org/10.1016/j.jneb.2015.08.005

Nickols-Richardson, S. M., Nelson, S. A., \& Corbin, M. A. (2014). Peer Nutrition Education in Childhood and Adolescence: Evidence-Based Guidance for Impactful Programs. Journal of Nutrition Education and Behavior, 46, S196. https://doi.org/10.1016/j.jneb.2014.04.211

Ogden, C. L., Carroll, M. D., Fryar, C. D., \& Flegal, K. M. (2015). Prevalence of Obesity among Adults and Youth: United States, 2011-2014. NCHS Data Brief, No. 219, 1-8.

Peterson, S., Duncan, D. P., Null, D. B., Roth, S. L., \& Gill, L. (2010). Positive Changes in Perceptions and Selections of Healthful Foods by College Students after a Short-Term Point-of-Selection Intervention at a Dining Hall. Journal of American College Health, 58, 425-431. https://doi.org/10.1080/07448480903540457

Schrader, P. G., \& Brown, S. W. (2008). Evaluating the First Year Experience: Students' Knowledge, Attitudes, and Behaviors. Journal of Advanced Academics, 19, 310-343. https://doi.org/10.4219/jaa-2008-775

Slining, M. M., \& Popkin, B. M. (2013). Trends in Intakes and Sources of Solid Fats and Added Sugars among U.S. Children and Adolescents: 1994-2010. Pediatric Obesity, 8, 307-324. https://doi.org/10.1111/j.2047-6310.2013.00156.x

Tagtow, A., \& Raghavan, R. (2017). Assessing the Reach of MyPlate Using National Health and Nutrition Examination Survey Data. Journal of the Academy of Nutrition and Dietetics, 117, 181-183. https://doi.org/10.1016/j.jand.2016.11.015

Thompson, K. L., Silver, C., Pivonka, E., Gutschall, M., \& Mcanulty, L. (2015). Fruit- and Vegetable-Focused Grocery Store Tour Training Kit to Promote Peer-on-Peer Nutrition Education Utilizing Nutrition and Dietetics Students. Journal of Nutrition Education and Behavior, 47, 472-476. https://doi.org/10.1016/j.jneb.2015.04.329

Topp, R., Speltz, J., Simenz, C., Zelm, P., \& Topp, J. (2014). Effect of a Personal Health and Fitness Course on Dietary Intake, Physical Fitness and Attitudes toward Wellness among College Students. Journal of Obesity \& Weight Loss Therapy, 4, 237. https://doi.org/10.4172/2165-7904.1000237

University of Delaware (2017). Facts \& Figures 2016-2017. University of Delaware. http://ire.udel.edu/ir/facts-figures

US Department of Agriculture (2015). NIH Body Weight Planner Added to USDA SuperTracker Food and Activity Tool. https://www.usda.gov/media/pressreleases/2015/07/20/nih-body-weightplanner-added -usda-SuperTracker-food-and-activity

US Department of Agriculture (2017). What Is MyPlate? https://www.chooseMyPlate.gov/MyPlate

Vadeboncoeur, C., Townsend, N., \& Foster, C. (2015). A Meta-Analysis of Weight Gain in First Year University Students: Is Freshman 15 a Myth? BMC Obesity, 2, 22. https://doi.org/10.1186/s40608-015-0051-7

Yahia, N., Wang, D., Rapley, M., \& Dey, R. (2016). Assessment of Weight Status, Dietary 
D. Jerome et al.

Habits and Beliefs, Physical Activity, and Nutritional Knowledge among University Students. Perspectives in Public Health, 136, 231-244.

https://doi.org/10.1177/1757913915609945 